\title{
A NATUREZA DOS NÚMEROS NA REPÚBLICA DE PLATÃO
}

\author{
Anastácio Borges de Araújo Jr.* \\ abaraujojr@uol.com.br
}

\begin{abstract}
RESUMO É incontestável a presença das matemáticas nos diálogos de Platão, todavia o alcance e o sentido desta presença é matéria de controvérsia entre os especialistas. Alguns acreditam que os temas matemáticos empregados nos diálogos são fantasias matemáticas, outros defendem baseados, sobretudo no testemunho de Aristóteles, que Platão teria substituído na sua hipótese as formas inteligíveis pelos números ideais. Sem tomar partido de antemão nestas querelas, o que propomos aqui é uma investigação acerca da natureza dos números fundamentada exclusivamente nos textos de Platão, particularmente orientada por uma passagem do livro VII do diálogo República (525 b11- c3), em que Sócrates diz o seguinte: "Seria, portanto, conveniente colocar este estudo, ò Glaucon, dentro de uma legislação e persuadir aqueles que vão participar das grandes coisas na cidade a irem ao cálculo e a aplicarem-se a ele, não nos seus afazeres privados, mas até chegarem à contemplação da natureza dos números através da própria intelecção (...)”
\end{abstract}

Palavras-chave Números, Platão, República, formas inteligíveis

ABSTRACT The presence of the mathematics in Plato's dialogues is unquestionable. However, its reach and sense is controversial for some specialists. Some believe that the mathematical themes employed in the dialogues are mathematical fantasies; on the other hand, others defend,

* Professor de Filosofia Antiga do Departamento de Filosofia da Universidade Federal de Pernambuco, UFPE. Recebido em 29/01/2010 e aprovado em 02/03/2010.

KRITERION, Belo Horizonte, nº 122, Dez./2010, p. 459-471. 
based on the Aristotle's testimonies, that Plato would have substituted the intelligible forms by the ideal numbers in his hypothesis. Having not taken part in the quarrel, we propose an investigation on the nature of the numbers based exclusively in Plato's texts, particularly oriented by the a passage in book VII of Republic (525 b11 - c3), in which Socrates says: "Then it would be fitting, Glaucon, to set this study down in law and persuade those who are going to participate in the greatest things in the city to go to calculation and to take it up, not after the fashion of private men, but stay with it until they come to the contemplation of nature of numbers with intellection itself (...)"

Keywords Numbers, Plato, Republic, intelligible forms

\section{Introdução}

É incontestável a presença das matemáticas nos diálogos de Platão, todavia o alcance e o sentido desta presença é matéria de controvérsia entre os especialistas. Alguns acreditam que os temas matemáticos empregados nos diálogos são fantasias matemáticas ${ }^{1}$, outros defendem baseados, sobretudo, no testemunho de Aristóteles ${ }^{2}$ que Platão teria substituído as formas inteligíveis pelos números ideais na sua Doutrina das Ideias. Sem tomar partido nesta querela, o que propomos aqui, antes, é uma investigação acerca da natureza dos números orientada por uma passagem do livro VII do diálogo República, em que Sócrates diz o seguinte:

"Seria conveniente, Gláucon, impor esse aprendizado por meio de uma lei e persuadir os que na cidade estão destinados a participar das mais altas funções a se interessarem pelo cálculo, dedicando-se a ele não nos seus afazeres privados, mas até que cheguem, só com o auxílio da intelecção, à contemplação da natureza dos números, não para a compra e venda como se fossem mercadores ou vendeiros, mas visando a aplicá-los na guerra e facilitar que a própria alma abandone o devir e se volte para a verdade e para a essência."”

1 Taylor, A. E. A Commentary on Plato's Timaeus. Oxford, Claredon Press, 1928. Reimpressão em 1962, pág. 98 apud VITRAC, Bernard. 'Les Mathématiques dans le Timée de Platon: le point de vue d'un historien des sciences' in PRADEAU, Jean-François. (org.) Études Platoniciennes. Paris: Belles Lettres, 2006, pág. 68, nota 165.

2 Ver em especial os livros $\mathrm{M}$ e $\mathrm{N}$ da Metafísica de Aristóteles.

3 Platão. A República: [ou sobre a justiça, diálogo político]. Tradução Anna Lia Amaral de Almeida Prado. São Paulo: Martins Fontes, 2006, 525 b11 - c3. Doravante simplesmente Rep. acompanhada da referência; observamos, ainda, que as citações, em geral, terão pequenas modificações nossas. 
Diferente dos homens que se utilizam do cálculo para obter vantagens particulares, o filósofo se prepara para participar dos assuntos da cidade e para isso é necessário dedicar-se ao cálculo tendo como objetivo a defesa da cidade e a compreensão intelectual da natureza dos números. Ou seja, aproximar-se do que é mais profundamente o número constitui uma tarefa filosófica que deve ser proporcionada àqueles que estão destinados a participar dos assuntos da cidade. Entretanto, além dos dois usos do cálculo sugeridos pelo trecho que acabamos de ler, usos estes que podemos chamar de vulgar e filosófico, conhecemos um terceiro uso para o qual Sócrates chamou atenção no livro VI da própria República ${ }^{4}$ : o uso praticado pelos homens que trabalham com a geometria e o cálculo. Ou seja, fica evidente que no diálogo República, além do uso vulgar do cálculo que é orientado pelo interesse particular, existem duas maneiras de se ocupar de noções como números, linhas, figuras: os que trabalham com estas noções tomando-as como se fossem realidades evidentes e compartilhadas por todos deduzindo daí as conclusões que se seguem, e aqueles que reconhecem estas noções e buscam a partir delas compreendêlas enraizadas numa experiência de inteligibilidade mais fundamental. Nosso trabalho tem como objetivo esclarecer, na medida do possível, em que consistem estas duas atitudes com relação aos números para tentar elucidar o sentido que há em investigar a natureza dos números na busca filosófica pela verdade. Antes de passarmos à análise dos textos, gostaríamos de fazer algumas breves considerações.

A primeira é que apesar de tratarmos da natureza dos números e de noções que pertencem ao domínio daquilo que, atualmente, chamamos matemática, isto será realizado de maneira muito indireta na medida em que a investigação filosófica encontra o cálculo como uma espécie de aliado na sua tarefa de pensar e compreender o pensamento. Ou seja, não gostaríamos de frustrar ninguém e declarar claramente que iremos examinar o papel do estudo dos números numa perspectiva filosófica.

Depois, é interessante colocarmos, ainda que esta informação seja banal para alguns, que não encontramos o termo matemática nos diálogos de Platão. O termo mathematikós só aparece duas vezes nos diálogos, no Sofista 219 c e no Timeu 88c, para designar o que concerne à aprendizagem e o matemático, indivíduo que estuda essa matéria. De resto aparecem nos diálogos vários outros termos derivados do verbo mantháno que significa aprender no sentido de assunto que se estuda ou conhece. Quer dizer: não há nos diálogos uma 
designação que unifique as várias atividades do conhecimento, tal como a aritmética e a geometria. No que se refere ao conhecimento matemático, gostaríamos ainda de esclarecer ainda que não saibamos, com precisão, qual era estado deste conhecimento na época de Platão, os escritos matemáticos mais antigos que temos acesso pertencem já ao período helenístico ${ }^{5}$, de tal modo que os diálogos platônicos, ao lado dos tratados aristotélicos, passam a ser as principais fontes no estudo da história desta ciência antes do período helenístico. Isto significa que temos, muitas vezes, que extrapolar o texto do diálogo e supor qual o conhecimento matemático que Platão possuía ao escrevê-los, coisa que de fato não sabemos.

Por último, com relação às fontes, gostaríamos de ressaltar que os trechos dos livros VI e VII da República que serão analisadas aqui em nosso trabalho são passagens bem conhecidas e comentadas por muitos interpretes, porém, são também textos muito difíceis em torno dos quais existem muitas controvérsias e há também uma certa tradição interpretativa que termina por dificultar o trabalho de qualquer um de nós que ainda insiste em estudar estes textos tão ricos e complexos. São passagens tão exploradas e desgastadas que para elas existem até denominações clássicas como analogia do sol e do bem, linha dividida, alegoria da caverna, como se ali tudo tivesse sido compreendido e não restasse mais nada a ser pensado. Queremos dizer que com relação a essas passagens é muito laborioso se distanciar das interpretações consolidadas e ler, simplesmente, o diálogo. Queremos tentar ler esses trechos acompanhando-os nos detalhes, não visando uma interpretação inovadora nem mesmo parafraseálos, mas examinando como eles ainda nos fazem pensar, pensando junto com eles e através deles. Para minimizar os problemas consultamos, além do texto grego, algumas traduções que para nós pareceram melhor se aproximarem do texto original, ou seja, que são mais literais, entre estas gostaríamos de destacar a versão para o inglês de Allan Bloom, trabalho este que muito nos auxiliou. Para as citações, utilizamos a tradução para o português de Ana Lia Amaral de Almeida Prado ainda que, às vezes, fizemos algumas poucas alterações. Passemos agora para análise do texto de Platão.

\section{A linha, as coisas visíveis e os dois modos de conhecer}

No final do livro VI da República, depois da metáfora do sol e do bem, Sócrates pede que Gláucon tome uma linha e que a corte em dois segmentos

5 Segundo Vitrac as obras mais antigas são: a "enciclopédia" matemática de Euclides, conhecida como Elementos, e alguns tratados, agrupados sob o título de Pequena Astronomia, atribuídos a Euclides, Autólico de Pitane, Aristarco de Samos, entre outros. Ver VITRAC, Bernard. Op. cit., pág. 11-12 . 
desiguais, atribui ao primeiro segmento o gênero visível e ao segundo o inteligível, e, novamente, solicita que corte cada um destes segmentos em dois seguindo a mesma proporção. De acordo a relativa claridade e obscuridade que tenham entre si, Sócrates mostra o gênero visível dividido em dois: a) imagens (eikónos $)^{6}$, quer dizer sombras $(\text { skiâs })^{7}$ e aparições (phantásmata) ${ }^{8}$ produzidas nas superfícies; b) aquilo de que são imagens, isto é, os seres vivos (zóon $)^{9}$ que nos rodeiam, tudo que é plantado (phyteutón $)^{10}$ e as espécies que são produzidas pela arte (skeuastón) ${ }^{11}$. Em seguida, Sócrates sugere que este mesmo visível terminou por ficar separado segundo o critério de verdade e não-verdade, deduzindo, então, que o opinável (doxastón) ${ }^{12}$ está para o cognoscível (gnōstón) ${ }^{13}$ de maneira similar que o semelhante, a imagem, está para aquilo com o qual se assemelha, o ser vivo ou objeto.

Embora saibamos que nesta passagem Sócrates enfrenta a dificuldade de definir a imagem como algo que é e não é verdadeiro, dificuldade esta decorrente da identidade estabelecida entre o ser e o verdadeiro e que será enfrentada só mais tarde no diálogo Sofista ${ }^{14}$, para nossa investigação o primordial é lembrar que Sócrates está, provavelmente, resgatando o conceito dýnamis definido no final do livro $\mathrm{V}^{15}$ da República, quando estabeleceu que as potências são espécies de seres dos quais devemos apenas observar a que se referem, o seu objeto, e como se realizam, o seu efeito. Assim, Sócrates estaria aqui confirmando que a opinião e o conhecimento são potências diferentes, pois se referem a coisas distintas completando-se de maneiras diversas. Para caracterizar o segmento visível, com suas duas partes, Sócrates descreve primeiramente as coisas que compõem cada segmento (imagens; seres vivos e artefatos), para em seguida dizer que a opinião se realiza a partir das coisas visíveis produzindo em nós a capacidade de emitir opiniões ou julgar. Numa relação analógica, podemos estabelecer que a imagem está para o objeto do

\footnotetext{
6 Rep., 509 e1.

7 Rep., 510 a1.

8 Rep., 510 a1.

9 Rep., 510 a5.

10 Rep., 510 a6.

11 Rep., 510 a6.

12 Rep., 510 a9.

13 Rep., 510 a9.

14 PLATÃO. Diálogos (O Banquete, Fédon, Sofista, Político). Seleção de textos de José Américo Motta Pessanha; tradução e notas de José Cavalcante de Souza, Jorge Paleikat e João Cruz Costa. $4^{a}$. Edição. São Paulo: Nova Cultural, 1987, (Os pensadores). Ver Sofista, 236 d9 e ss: "É que, realmente, jovem feliz, nos vemos frente a uma questão extremamente difícil; pois, mostrar e parecer sem ser, dizer algo, sem entretanto, dizer com verdade, são maneiras que trazem grandes dificuldades, tanto hoje, como ontem e sempre. Que modo encontrar, na realidade, para dizer ou pensar que o falso é real, sem que, já ao proferilo, nos encontremos enredados na contradição?"
}

15 Rep., 477 c e ss. 
qual é imagem, assim como a opinião relaciona-se com o conhecimento ou ciência, quer dizer, a imagem é imagem de algo, assim como a opinião é uma apreensão imperfeita de algo que pode ser conhecido de maneira melhor. Exemplificando, de maneira similar alguém que conhece um cavalo apenas por uma pintura deste animal, restrito a uma situação cognitiva imperfeita, equivale ao homem que julga a realidade inteligível por suas opiniões baseadas na experiência visível. A opinião (dóxa) é uma potência que se realiza a partir da visibilidade das coisas, o que parece, produzindo em nós efeitos tais como a imaginação (eikasía) ou a convicção (pístis), conforme veremos a seguir. Vejamos agora o trecho que se refere ao inteligível, diz então Sócrates:

“- De outro lado, examina também como deve ser cortado o segmento do inteligível.

- Como?

- Da seguinte maneira: numa parte deste segmento, a alma, usando como imagens as coisas que anteriormente eram imitadas, é forçada a procurar a partir de hipóteses, caminhando na direção não do princípio, mas do fim; na outra parte do segmento, porém, caminha da hipótese ao princípio livre de hipóteses, sem servir-se de imagens como no outro caso e realiza seu percurso só através das próprias formas. "16

Curiosamente, Sócrates não descreve o segmento inteligível do mesmo modo como descreveu o segmento visível, isto é, enumerando os seus objetos, tal como esperávamos. Em vez disso, descreve o modo como a alma conduz sua busca e os instrumentos que utiliza para investigar. Como observou com precisão Monique Dixsaut ${ }^{17}$, o princípio que, de início, estabelece a separação do segmento inteligível é se a alma utiliza ou não imagens. Poderíamos ainda completar: ao lado deste princípio, o que vai determinar os dois cortes do segmento inteligível é o modo como a alma caminha (poreuoménē). Se a alma prossegue sua marcha a partir da hipótese em direção ao fim (teleutế) isto é, a uma conclusão, ou se ela vai em direção ao princípio (archế), ao que não admite hipóteses, isto é, caminhando para o que está na origem.

A primeira parte do segmento inteligível é caracterizada pela presença da imagem no movimento de apreensão da alma, imagem daquilo que no segmento visível era imitado, e pela direção que governa sua reflexão que busca um encadeamento de consequências daquilo que foi colocado inicialmente até uma conclusão na qual termina o movimento da alma. Podemos dizer que a alma na sua busca por inteligibilidade é levada a criar uma imagem a partir da qual se vê forçada a buscar hipóteses que levam a outras hipóteses retirando 
deste processo suas próprias conclusões quando chega, então, ao término de sua jornada. Os geômetras criam as imagens matemáticas como os artesões produzem os seus artefatos para, em seguida, deduzirem seus raciocínios a partir destas imagens. A segunda parte do inteligível, ao contrário, caracterizase pela ausência de imagem nos movimentos de apreensão da alma que caminha, a partir da hipótese, em busca do saber que a fez colocar a hipótese, o princípio, aquilo sem o que não poderia ter qualquer hipótese. O seu esforço é o de buscar a condição de possibilidade de sua reflexão. O texto do diálogo é bem difícil e a reação de Gláucon, acompanhada do desdobramento do diálogo deixam isso claro:

“- Não compreendi suficientemente, disse ele, o que disseste.

- Ora explico outra vez... Com a introdução que vou fazer, entenderás com mais facilidade. Creio que tu sabes que aqueles que se ocupam com a geometria, com cálculos e assuntos como esses põem como hipótese o par e o ímpar, as figuras, três espécies de ângulos e outras coisas afins, de acordo com o objeto de sua investigação, e, de um lado, como se as conhecessem, tomam-nas como hipóteses e acham que não têm de prestar contas nem a eles mesmos nem aos outros sobre isso que, segundo eles, é coisa evidente para qualquer um, e, de outro lado, começando a partir dessas hipóteses, já ao expor o restante, de maneira consequente, acabam por chegar à demonstração daquele ponto que os levou ao esforço de investigação. "18

O texto ainda é difícil. Entretanto, Sócrates espera que o exemplo tirado do domínio das matemáticas torne o assunto mais compreensível para seu interlocutor. Sócrates faz Gláucon lembrar a atividade dos geômetras e dos homens de cálculo que se utiliza de noções como o par, o ímpar, as figuras e as três espécies de ângulos como coisas evidentes a todos e que não exigem qualquer justificação ou esclarecimento. Quer dizer, se utilizam de noçõesimagens que acreditam ser claras para deduzir raciocínios e reflexões que levam a uma conclusão a partir daquilo que os levou a investigar. Neste modo de conhecer o inteligível o investigador se serve de formas visíveis ainda que não esteja pensando exatamente nelas, mas naquelas com as quais a forma visível tem semelhança. "Discutem a respeito do quadrado em si, da diagonal em si, e não sobre a diagonal desenhada (...)."'19. Tentam ver nos desenhos aquilo que não podem ver, a não ser que utilizem imagens através da reflexão como fazem os geômetras.

A reflexão (diánoia) utiliza a imagem como tentativa de aproximar-se daquilo que não pode ser visto por imagem. Tal experiência, limitada pelo seu 
instrumento, não utiliza os meios adequados para atingir aquilo que realmente visa, assim, ela nos leva a ver sensivelmente aquilo que só pode ser visto pelo olhar da inteligibilidade. A reflexão só pode encadear seus raciocínios apoiada por imagens e, neste processo, esquece que as imagens são recursos criados e utilizados por ela mesma e não as realidades verdadeiras, confundido, enfim, as imagens com aquilo de que são imagens. Se as imagens trabalhadas pelos geômetras - números, figuras, e ângulos - fossem as próprias realidades, haveria, então, objetos intermediários entre os sensíveis e os inteligíveis. Esta tese, tão popularizada como outras, merece ser, em nossa opinião, reexaminada. Aliás, Monique Dixsaut sugere com perspicácia:

"Porém, dos exemplos tomados por Sócrates se poderia deduzir que, se o pensamento dianoético é dito «intermediário entre a opinião e a inteligência », é por que ele se aplica aos objetos eles mesmos intermediários, as Ideias matemáticas. Existiriam então duas espécies de realidades inteligíveis? Esta interpretação foi muitas vezes predominante, ela recebeu dos Neoplatônicos sua notoriedade. Entretanto, a colocação de realidades inteligíveis inferiores, intermediárias entre as realidades sensíveis e as Formas, não tem nenhum fundamento textual. O Par, o Ímpar, assim como o Dois e o Três, são no Fédon exemplos destas Formas que conferem seus nomes ou suas propriedades às coisas que delas participam. É então bem mais provável que a diferença entre os dois segmentos do inteligível não pertence à natureza dos objetos, mas ao modo de conhecê-los." ${ }^{20}$

Pelo que vimos até aqui, baseados na interpretação dos textos citados do diálogo República, o que diferencia as duas partes do segmento inteligível são modos de processar o conhecimento e não objetos da inteligibilidade. Faltanos examinar o outro modo de conhecer, a intelecção (nóesis), que caracteriza o segundo segmento do inteligível que é descrito por Sócrates da seguinte maneira:

"Pois bem! Entende o que eu digo da outra parte do inteligível, aquela que o lógos toca pela potência da dialética, considerando as hipóteses não como princípios, mas realmente como hipóteses, como degraus e pontos de apoio, para chegar ao que é livre de hipóteses, princípio de tudo. Num movimento inverso, por sua vez, presa a tudo que depende desse princípio, vai descendo na direção do fim e, sem servir-se de

20 DIXSAUT, Monique. Op. Cit., pág 77. "Mais des exemples pris par Socrate on pourrait déduire que, si la pensée dianoétique est dite «intermédiaire entre l'opinion et l'intelligence», c'est parce qu'elle s'applique à des objets eux-mêmes intermédiaires, à des Idées mathématiques. Existe-t-il donc deux espéces de réalités intelligibles ? Cette interprétation a été maintes fois avancée, elle a reçu des Néoplatoniciens ses lettres de noblesse. Cepedant la position de réalités intelligibles inférieures, intermédiaires entre les réalités sensibles e les Formes, n'a aucun fondement textuel. Le Pair, I'Impair, tout comme le Deux ou le Trois, sont dnas le Phédon des exemples de ces Formes qui confèrent leur nom ou leur propriété aux choses qui en participent. II est donc bien plus probable que la différance entre les deux segments de l'intelligible ne tienne pas à la nature des objets mais à la façon de les connaître." 
nada que seja sensível, mas apenas das próprias formas, por meio delas e por causa delas, acaba por chegar às formas. " 21

Ao contrário da reflexão, a intelecção não utiliza imagens e não toma as hipóteses por princípios. Parte das hipóteses em busca daquilo que permite a alma colocar hipóteses. Essa segunda parte do inteligível é tocada pelo lógos, quer dizer, experimentamos a inteligibilidade de um modo muito sutil pela capacidade de ir e vir, movimentando a alma pelo seu diálogo silencioso, saltando de hipótese em hipótese, até chegar ao que é livre de hipótese. Ou seja, até chegarmos àquilo que exige ser posto sem qualquer condição e por isso princípio de todas as outras hipóteses. É possível aqui lembrar o diálogo Sofista no qual o Estrangeiro demonstra que entre os gêneros supremos há um sem o qual nenhum dos outros gêneros pode ser pensado, o gênero do ser que se comunica com todos os outros os fazendo serem o que são. Sócrates faz Gláucon compreender a contínua tarefa (sychnón érgon) ${ }^{22}$ filosófica que consiste em fazer do conhecimento das coisas que são, conhecimento este iluminado pela ciência da dialética (tếs tôu dialégesthai epistêmēes) ${ }^{23}$, algo mais claro que as demonstrações matemáticas. Tal conhecimento é aquilo que pode e deve ser chamado de inteligência.

Sócrates conclui o livro VI estabelecendo as quatro afecções que surgem na alma (pathếmatha en tếi psychêi) ${ }^{24}$ correlativas às quatro partes dos dois segmentos examinadas: a intelecção que se refere a mais de cima, a reflexão que se relaciona com a segunda, a terceira é a confiança e, por último, a imaginação. Devemos agora ir em direção ao uso filosófico das matemáticas, apresentado no livro VII do diálogo República ${ }^{25}$, e procurar compreender mais profundamente a intelecção como outro modo de conhecer o inteligível e o significado de sua relação com a natureza dos números.

\section{A busca pela natureza do número}

No livro VII, depois de apresentar a alegoria da caverna, Sócrates pergunta a Gláucon, como devem formar os homens para que eles possam sair da condição de obscuridade em que se encontram e ir em direção à luz, tendo acesso a uma maior inteligibilidade. "Qual seria (...) o aprendizado que 
arrasta a alma, levando-a daquilo que vem a ser até aquilo que é? "26 Qual é o conhecimento útil aos homens guerreiros, que venha juntar-se à ginástica e à música e que não seja uma arte destinada aos trabalhadores manuais? Sócrates sugere algo que se aplique a todas as coisas, algo que é comum (koinón ${ }^{27}$ a todas as artes, reflexões e ciências. Além disso, este estudo está entre as primeiras coisas que são necessárias aprender:

"- Este aprendizado ordinário, disse eu, que consiste em distinguir o um, o dois e o três. Digo em resumo o número e o cálculo. Ou não é o caso com eles de que toda arte e ciência forçosamente fazem usos deles?

- É bem isso que acontece, disse. (...)

- Que outro aprendizado, disse eu, poremos como necessário para o homem guerreiro do que o poder calcular e contar?

- Entre todos, disse, é o mais necessário, se ele pretende entender qualquer coisa que seja das linhas de batalha, mas, sobretudo, se apenas pretende ser um homem. "28

Enumerar e calcular constitui um saber comum que penetra todas as artes, reflexões e ciências. É um dos primeiros aprendizados do ser humano, tornando-o humano e por isso presente em todos os demais estudos. Porém, ninguém utiliza este estudo corretamente, embora ele seja capaz de conduzir o homem do que vem a ser em direção ao que é. Entre as sensações existem aquelas que são banais e outras que convidam a inteligência para a investigação, por exemplo, as que produzem sensações contrárias e fazem o homem apelar à inteligência por uma inspeção. Sensações opostas tais como leveza e de peso ou de grandeza e pequenez incitam à inteligência a examinar se são duas sensações contraditórias sobre o mesmo objeto ou sobre coisas diferentes. Indo em frente na sua investigação, decorre à inteligência questionar: afinal o que é a grandeza? De maneira análoga, a unidade é uma dessas noções que se repararmos apenas nas coisas sensíveis já não saberemos o que é o um, pois encontramos em cada unidade uma multiplicidade infinita. Para resolver este impasse a inteligência se vê constrangida a buscar o que é a unidade, sua inteligibilidade. Apenas no domínio do inteligível a alma poderá ver que é possível conceber a unidade integrada à multiplicidade sem deixar de ser uma unidade. Numa comunidade de múltiplas formas originárias, aliás, não podemos esquecer que na República o tema da comunhão (koinōnía ${ }^{29}$ das formas já se encontra sugerido, a unidade se encontra em relação co-originária 
com a multiplicidade. Neste sentido, os números fazem parte da comunidade de formas inteligíveis. Assim, justifica-se filosoficamente a busca pela natureza inteligível dos números que significa procurar sua origem, seu princípio de inteligibilidade e sua razão de ser. Complementa então Sócrates:

“- E agora, disse eu, depois que se falou do aprendizado do cálculo, também fico pensando como ele é refinado e como, de muitas formas, é útil para nós em vista do que desejamos, caso alguém se ocupe dele para o conhecimento e não para o comércio.

- Em que sentido?

- No sentido que acabamos de dizer. Ele conduz a alma com muita força em direção ao alto e obriga-a a discutir a respeito dos números neles mesmos, sem jamais admitir discussão, caso alguém lhe proponha números associados aos corpos visíveis ou tangíveis. Deves saber que os peritos nesses assuntos, se alguém tentar, na discussão, dividir a unidade em si, fazem caçoada e não admitem isso. Se, porém, tu tentar quebrar a pequena moeda eles a multiplicam com receio que a unidade não se mostre una, mas como muitas partículas.

- O que dizes é bem verdade, disse.

- O que pensarias, Gláucon, se alguém lhes perguntasse: 'Ó admiráveis homens, a respeito de que números estais a discutir, entre os quais estão a unidade, tal como vós entendeis que existem, cada qual igual a outra, e sem diferir em nada, nem conter qualquer parte em si?' Que parece que eles responderiam?

- Aqui está o que eu diria... Eles falam de números que só podem ser pensados e não podem ser tratados de outra maneira. "'30

As noções matemáticas tais como números e figuras, ganham sentido quando enraizadas no inteligível. Definir noções matemáticas e dai tirar consequências coerentes não faz com que esta atividade demonstrativa se converta em um saber. Se ocupar com números implica, necessariamente, relacionar-se com o inteligível, ainda que o matemático ignore tal fato e acredite estar trabalhando com noções claras por que são definidas e demonstradas. $\mathrm{O}$ número é, em última instância, o número inteligível. Sua natureza é tal que faz com que o uso filosófico das matemáticas converta tais artes, os estudos matemáticos, em atividades preparatórias para a intelecção filosófica.

Porém, para nossa investigação o fundamental é que é possível admitir um alinhamento entre a racionalidade matemática e a racionalidade filosófica, ou seja, se, por um lado, os números podem ser investigados nas suas relações recíprocas, ou mesmo nas suas relações com as coisas sensíveis estabelecendo o domínio da diánoia e se, por outro lado, é possível investigar os números indo em direção ao princípio que lhes fornece inteligibilidade, estabelecendo o domínio da nóesis, parece-nos que é porque o número possui, assim como 
todas as outras formas inteligíveis, uma dupla e paradoxal natureza: é algo em si que mantém sua identidade, unidade e permanência e algo que está em relação que é capaz de afetar-nos. Passemos então, para concluir, para um breve comentário desta dupla característica das formas inteligíveis.

\section{A paradoxal natureza do inteligível}

No livro II da República, depois de um debate caloroso entre Sócrates e Trasímaco, Gláucon assume a discussão e convida Sócrates para continuar a investigação. Segundo Gláucon, há três espécies de bens: a) aqueles que apreciamos por si mesmos, como a alegria ou prazeres inofensivos com os quais nos deleitamos, somente, por possuí-los; b) aqueles de que gostamos em si mesmos e pelas consequências que trazem, tais como o pensamento, a vista e o ser saudável; c) aqueles que em si são penosos, mas que a partir deles conseguimos alguns benefícios: os exercícios da ginástica, os tratamentos médicos e as outras atividades que nos proporcionam dinheiro e saúde, por exemplo. Gláucon, então, questiona: em qual dessas categorias de bens devemos colocar a justiça? Ao que Sócrates responde: "Eu creio que na mais bela espécie, disse eu, naquela que, por si mesma e também pelo que dela decorre, quem quer ser feliz deve amar"31

Aqui para nós surge o profundo mistério da inteligibilidade. Não faz sentido a nenhum homem buscar algo que fosse só em si mesmo. O diálogo Parmênides mostra o quanto seria absurdo uma realidade separada, o uno, que não tivesse qualquer relação com as outras realidades, porém este mesmo diálogo aponta o quanto seria ininteligível se estivéssemos numa cadeia infinita de relações sem que algo que seja colocado absolutamente, isto é, algo que se põe no início da cadeia e dê sentido a todo o resto. Deste modo, a forma inteligível como uma hipótese tem que ser colocada e sendo colocada tem que, também, manter relação com todas as outras formas e essas por sua vez com todas as outras coisas. Caso contrário, a hipótese inteligível não teria qualquer sentido e Aristóteles teria completa razão em suas críticas a Platão. A justiça deve por sua perfeição e completude ocupar um lugar entre os mais belos dos bens. Aqueles que são amados em si mesmos, na sua constante relação que mantém com todas as coisas e pelos seus efeitos e realizações. Podemos então compreender todo delineamento da pólis através do lógos, a fundação da cidade em argumentos realizada na República, como a produção de uma 
imagem dianoética fruto da reflexão, embora inspirado pelas realidades que só podem ser tocadas pela inteligência. Eis em que consiste para nós a hipótese inteligível; a aposta que existem realidades que tornam nossa experiência minimamente compreensível, pois de alguma forma temos acesso ao ser verdadeiro e inteligível. Agora é possível entender a força e a ênfase com que Sócrates recomenda o estudo da natureza dos números, transformando este estudo em matéria de legislação na cidade, pois com este aprendizado podemos nos aproximar do mistério da inteligibilidade.

\section{Referências}

DIXSAUT, Monique. Platon: Le Desir de Comprendre. Paris: Vrin, 2003 PLATÃO. A República: [ou sobre a justiça, diálogo político]. Tradução Anna Lia Amaral de Almeida Prado. São Paulo: Martins Fontes, 2006.

PLATÃo. Diálogos (O Banquete, Fédon, Sofista, Político). Seleção de textos de José Américo Motta Pessanha; tradução e notas de José Cavalcante de Souza, Jorge Paleikat e João Cruz Costa. 4a . Edição. São Paulo: Nova Cultural, 1987. (Coleção Os pensadores).

VITRAC, Bernard. 'Les Mathématiques dans le Timée de Platon: le point de vue d'un historien des sciences' IN PRADEAU, Jean-François. (org.) Études Platoniciennes. Paris: Belles Lettres, 2006. 